\title{
ENVIRONMENTAL IMPACT DUE TO THE DOUBLING OF GREEN HOUSE GASES THROUGH GLOBAL CLIMATE MODEL
}

\author{
Siddharth Nahta ${ }^{1}$, Siddhant Singh ${ }^{2}$ \\ ${ }^{1,2}$ B.Tech Final Year, Department of Civil Engineering, SRM University, Chennai, Tamilnadu, India
}

\begin{abstract}
Anthropogenic carbon is responsible for both global warming and ocean acidification. Efforts are underway to understand the role of the ocean in a high $\mathrm{CO}_{2}$ world on a global context. Atmospheric carbon dioxide $\left(\mathrm{CO}_{2}\right)$ concentration has continued to increase and is now almost 100 ppm above its pre-industrial level. Combining our reconstruction with the known history of the anthropogenic emissions gives us a more precise and detailed view of the terrestrial biosphere sink. The term 'Greenhouse Effect' refers to the way certain gases trap heat in the atmosphere, much as the glass in a greenhouse prevents rising warm air from escaping. The greenhouse effect is a process where energy from the sun readily penetrates into the lower atmosphere and onto the surface of Earth and is converted to heat, but then cannot freely leave the planet. Due to the presence of certain greenhouse gases that trap heat, like carbon dioxide, methane, water vapour, and CFCs, the atmosphere retains the suns radiation and warms up the planet. By increasing the abundance of these gases in the atmosphere, humankind is increasing the overall warming of the Earth's surface and lower atmosphere, a process called "global warming. $\mathrm{CO}_{2}$ is a greenhouse gas and as the IPCC report shows, its radiative effect is greater than that of all the other anthropogenic GHG gases.
\end{abstract}

Our efforts have been to try and understand the impact of doubling the concentration of $\mathrm{CO}_{2}$ and thereby, understand the impacts of this increase on important physical processes of nature like evaporation, precipitation, snow cover, surface runoff, snow depth, etc. The ecosystem is surviving due to the balance maintained within all the components. Drastic increase in any component of this balance can prove to be quite destructive. Since the existence of biological cosmos is dependent upon such processes, we had attempted to understand the relationship between these components based upon the feedback generated.

Keywords: Anthropogenic carbon, Acidification Biological cosmos Evaporation, Ecosystem, Greenhouse gas, Precipitation, Snow cover, Surface runoff, Terrestrial biosphere.

\section{INTRODUCTION}

The term 'Greenhouse Effect' refers to the way certain gases trap heat in the atmosphere leads to global warming and climate change. Natural events and human activities are believed to be contributing to an increase in average global temperatures. This is caused primarily by increases in "greenhouse" gases such as $\mathrm{CO}_{2}$. $\mathrm{CO}_{2}$ though not the most potent of GHGs, is the most significant one. Human activity has caused an imbalance in the natural cycle of the greenhouse effect and related processes. The 2007 Fourth Assessment Report compiled by the IPCC (AR4) noted that "changes in atmospheric concentrations of GHGs and aerosols, land cover and solar radiation alter the energy balance of the climate system", and concluded that "increases in anthropogenic GHGs concentrations is very likely to have caused most of the increases in global average temperatures since the mid-20th century". In AR4, "most of" is defined as more than $50 \%$. Here we develop GCM to analysis the environmental impact when GHGs gets doubled in the future as per the present trend of increase in GHGs. Global climate models (GCMs) are mathematical formulations of the processes that comprise the climate system. Climate models can be used to make projections about future climate and the knowledge gained can contribute to policy decisions regarding climate change. An advantage of GCMs is their ability to perform multiple simulation experiments using different greenhouse gas emissions scenarios.

\section{SETUP}

\subsection{Normal Climate}

To ensure the climatic aspect of study, the time scale used was from 1950 to 2130 . Initially the concentrations of all green house gases were kept at values of 1950. From year 1950 to 1999 in order to include the observed $\mathrm{CO}_{2}$, we entered data file of carbon dioxide for that period. From year 2000 we entered the data file from IPCC for A1_F1 scenario, which is often termed as "business as usual", a trend $\mathrm{CO}_{2}$ has been following for some time. Enabling this trend of carbon dioxide all other greenhouse gas concentration were kept at the same value as in 1950s. In order to replicate the actual condition to model we uploaded the observed sea surface temperature in 
ocean mode. This setup was run and all the information regarded were assumed to depict current state of atmosphere, extrapolated to 2130 .

\subsection{Perturbed Climate}

In order to implement a large change in the atmospheric composition of the climate, we doubled the concentration of all greenhouse gases as the initial condition of the atmosphere in the year 1950. From the year 1950 to 1970 a linear trend was enabled with $0.3 \%$ change in the concentration of carbon dioxide per year. From 1971 to 2130 the trend was assumed to be exponential with $0.75 \%$ change in concentration of carbon dioxide per year. The concentration of greenhouse gases was kept constant at double the value in 1950. No trend was enabled in other gases. We uploaded the observed sea surface temperature in ocean mode. This setup was run and all the information regarded were assumed to depict state of atmosphere that would occur when the concentration of carbon dioxide was doubled.

\section{OBSERVATIONS}

The observations and the effects of doubling of $\mathrm{CO}_{2}$ are shown by taking the changes happening on some important processes.

\subsection{Annual Evaporation}

The image above is the difference of evaporation (changes in evaporation) that happened because of the doubling of $\mathrm{CO}_{2}$ effect. It is very clear that the evaporation increases in many parts of the world. $\mathrm{CO}_{2}$ as a greenhouse gas leads to greenhouse effect and increases the temperature of the earth, which leads to more and more evaporation. More effect is observed near the poles where melting of ice takes place due to higher temperature and thus more evaporation takes place. The observations is highly variable depending upon the geographic location of the area. For instance annual evaporation is increasing especially in South America, Antarctica and parts of Australian continent by 0.12 to 0.26 $\mathrm{mm} /$ day. However parts of Indian subcontinent, Thailand, Cambodia, Vietnam, Japan saw a decrease in annual evaporation by 0.5 to $0.6 \mathrm{~mm} /$ day.

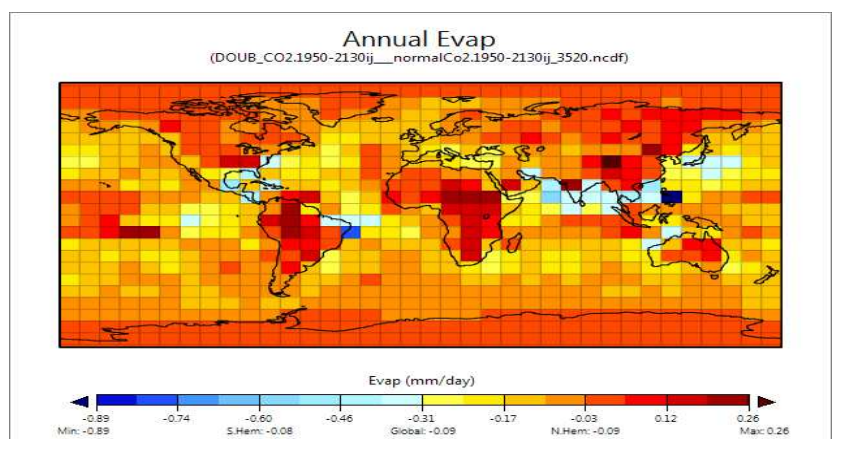

Fig. 3.1 Difference Observed in Annual Evaporation

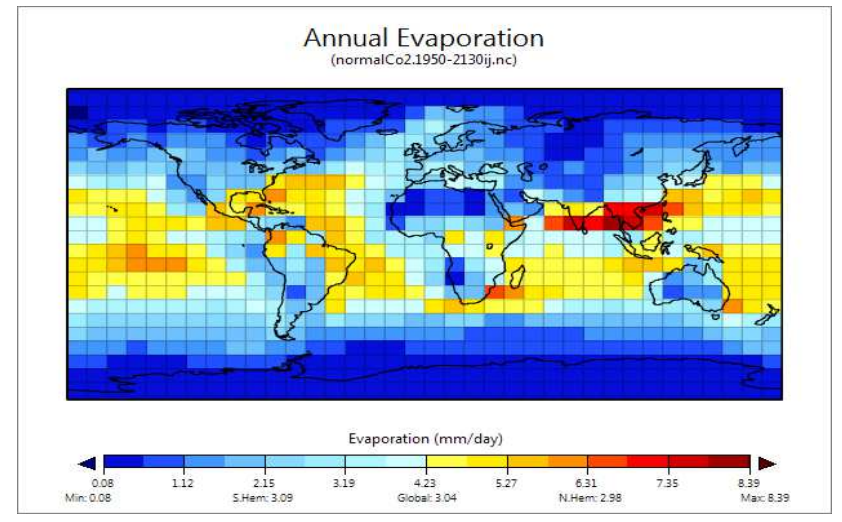

Fig. 3.2 Annual Evaporation for normal $\mathrm{CO}_{2}$ Trend during period of 1950-2130

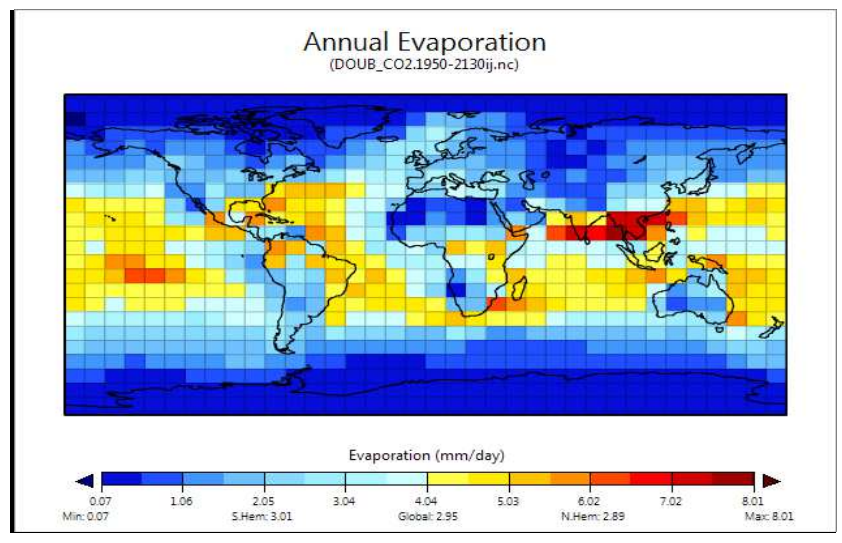

Fig. 3.3 Annual Evaporation after doubling the $\mathrm{CO}_{2}$ during period of 1950-2130

\section{Maximum difference observed $=0.26 \mathrm{~mm} /$ day \\ Minimum difference observed $=\mathbf{- 0 . 8 9} \mathrm{mm} / \mathrm{day}$}

\subsection{Annual Precipitation}

It is very clear to observe that annual precipitation increases in areas where evaporation increased and it decreased in areas where evaporation decreased.

The rate of precipitation around the Indian subcontinent has decreased by almost $0.9 \mathrm{~mm}$ per day. A small decrease is also distinctly visible in Latin American countries (but mostly over oceans) by almost $0.2 \mathrm{~mm}$ per day.

The fig. 3.2 shows the difference in precipitation observed by doubling effect of $\mathrm{CO}_{2}$ compared to the normal $\mathrm{CO}_{2}$ trend.

Maximum difference observed $=0.58 \mathrm{~mm} / \mathrm{day}$

Minimum difference observed $=\mathbf{- 1 . 4 5} \mathrm{mm} / \mathrm{day}$ 


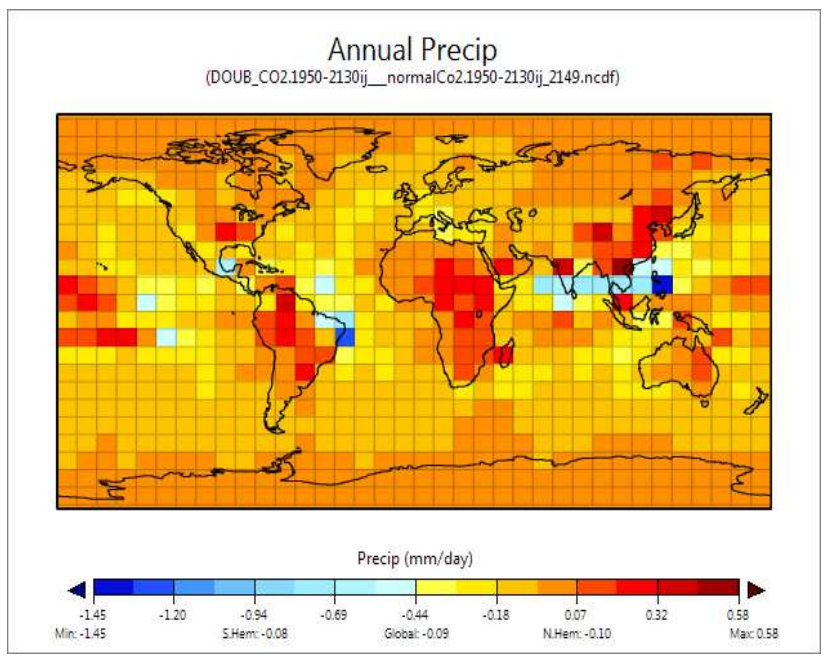

Fig. 3.2 Difference observed in Annual Precipitation

\subsection{Annual Surface Temperature}

It is absolutely clear that doubling the $\mathrm{CO}_{2}$ increase the annual surface temperature and the fig. 3.3 represents exactly the same.

The fig.3.3 shows the difference in annual surface temperature between the doubling effect of $\mathrm{CO}_{2}$ and the normal $\mathrm{CO}_{2}$. We clearly observe the increase in temperature throughout the world. Most of the increase in temperature is observed near the poles where annual surface air temperature increase is about 1-2 degree Celsius.

\section{Maximum Difference observed $=2.05$ degree Celsius}

\section{Minimum Difference observed $=0.0$ degree Celsius}

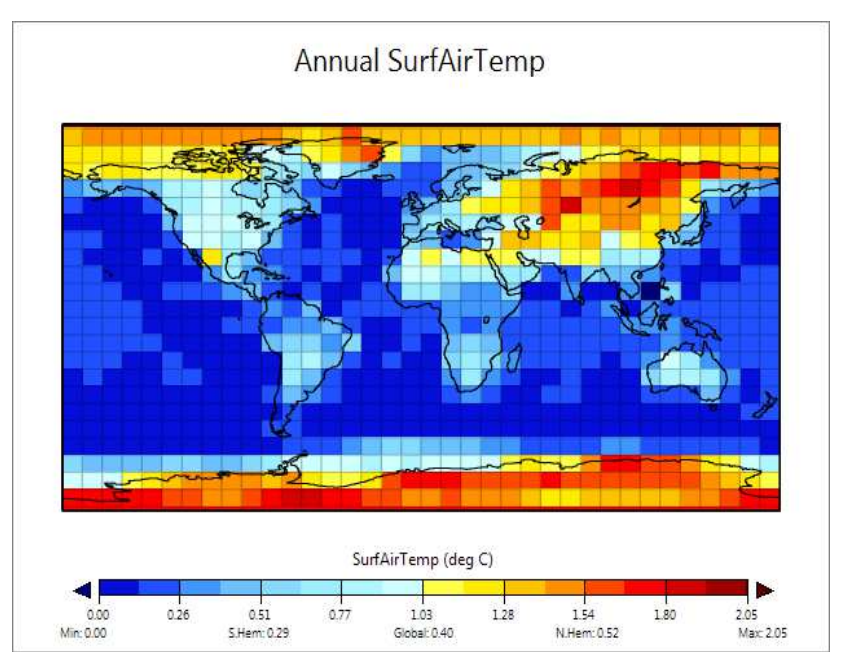

Fig. 3.3 Annual Surface Air Temperature

\subsection{Annual Planetary Albedo}

Albedo is a measure of the reflectivity of a surface. The albedo effect when applied to the Earth is a measure of how much of the Sun's energy is reflected back into space.

The most significant projected impact on albedo is through future global warming. With the exception of Antarctic seaice, recently increasing by $1 \%$ a year, nearly all the ice on the planet is melting. As the white surfaces decrease in area, less energy is reflected into space, and the Earth will warm up even more. It is clearly visible that all the ice except Antarctica is melting fast and thus in those areas albedo (reflectivity) is decreasing and thus the earth is getting warmed up.

\section{Maximum Difference observed $=0.51 \%$}

\section{Minimum Difference observed $=\mathbf{- 1 . 1 5 \%}$}

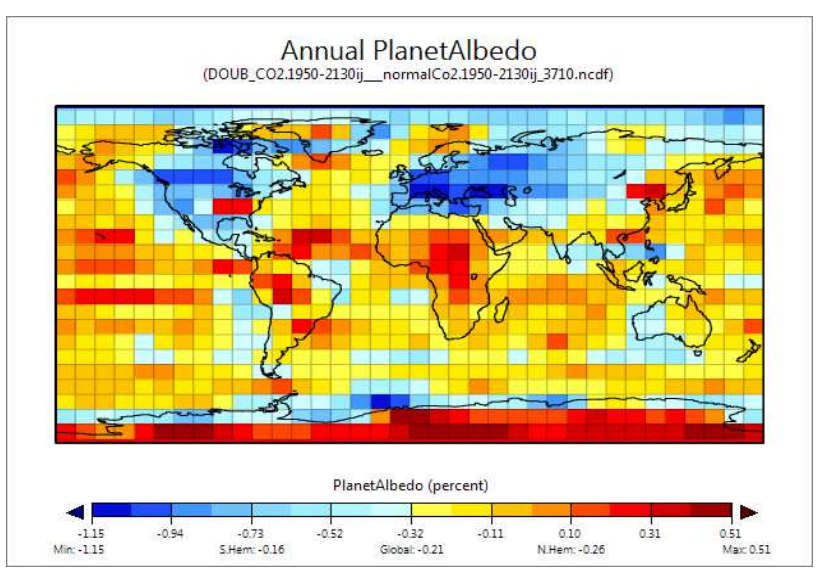

Fig. 3.4 Difference observed in Annual Planet Albedo

\subsection{Annual Snowfall}

The model indicates that the majority of the planet would experience less snowfall as a result of warming due to a doubling of atmospheric carbon dioxide. In North America, the greatest reductions in snowfall will occur along the northeast coast, in the mountainous west, and in the Pacific Northwest. In very cold regions of the globe, however, snowfall will rise because as air warms it can hold more moisture, leading to increased precipitation in the form of snow. Antarctica will get more snow with increase in $\mathrm{CO}_{2}$ concentration. 


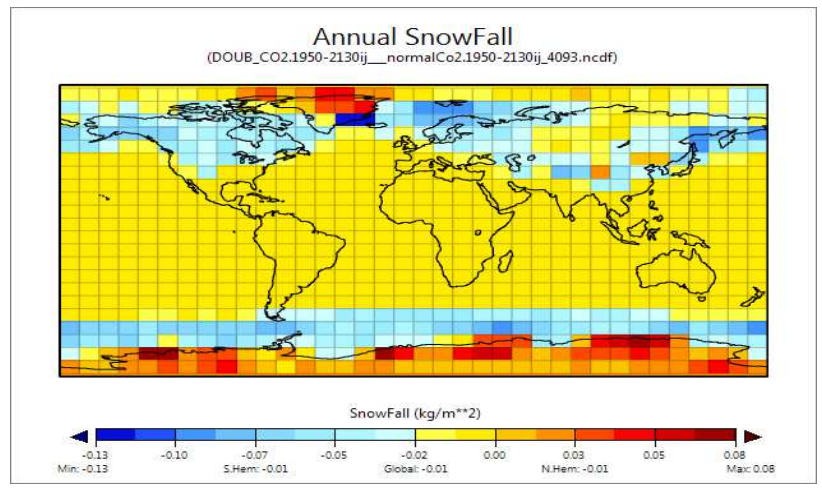

Fig. 3.5 Difference observed in Annual Precipitation

\subsection{Net Heating at Surface}

One of the most important characteristic of greenhouse gases, especially carbon dioxide in general is its influence and relationship with temperature. On increasing the concentration of carbon dioxide an overall increase in earth temperature was expected. However like evaporation and other processes the pattern of this change was very peculiar and interesting. Annual net heat surface shows a pattern very similar to that exhibited by evaporation. This develops a close link between both the processes and is a signature of the interdependence of such processes on each other. South America, Antarctica and parts of Australia continent, north eastern Russia and central China have overall negative annual heat surface by almost 1 to $2 \mathrm{~W} / \mathrm{m}^{\wedge} 2$ when compared to normal concentration scenario. These are the same locations where evaporation was higher. Thus we can conclude that by doubling the concentration of $\mathrm{CO}_{2}$ the rates of evaporation will be higher in these regions and that process in turn cools down the surface as heat is lost in the process.

In similar fashion, parts of Indian subcontinent, Thailand, Cambodia, Vietnam, Japan who saw a decrease in annual evaporation by 0.5 to $0.6 \mathrm{~mm}$ per day, have higher net heat surface by about $15 \mathrm{~W}$ per $\mathrm{m} 2$, which is consistent with our conclusion.

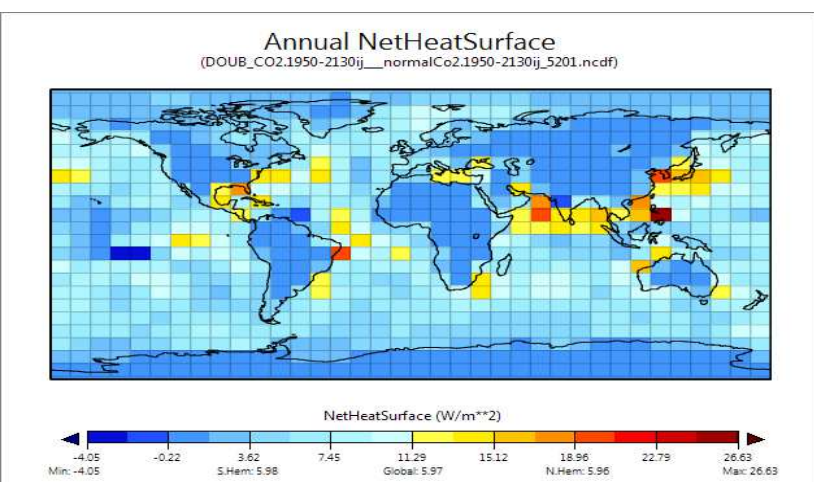

Fig. 3.6 Annual Net heating at surface

\subsection{Other Important Figures (Changes)}

\subsubsection{Annual Max Surface Temperature}

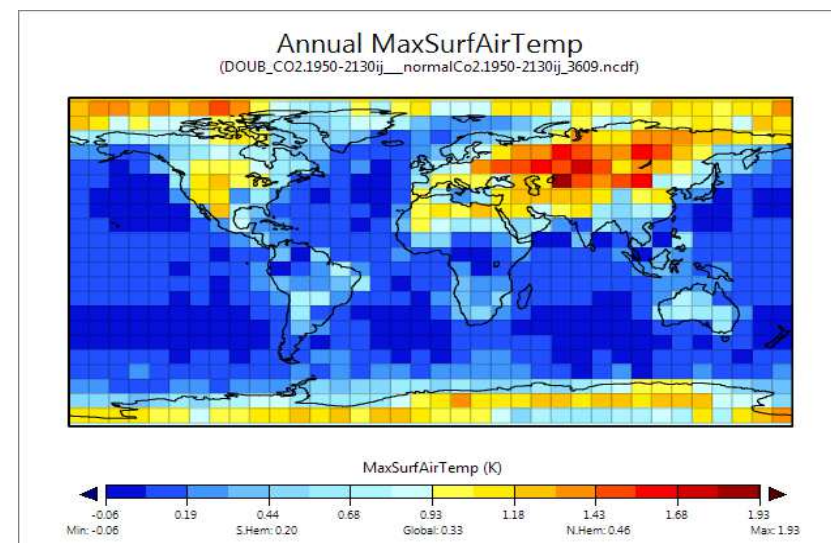

Fig. 3.5 Annual Max Surface Air Temperature

\subsubsection{Annual Minimum Surface Temperature}

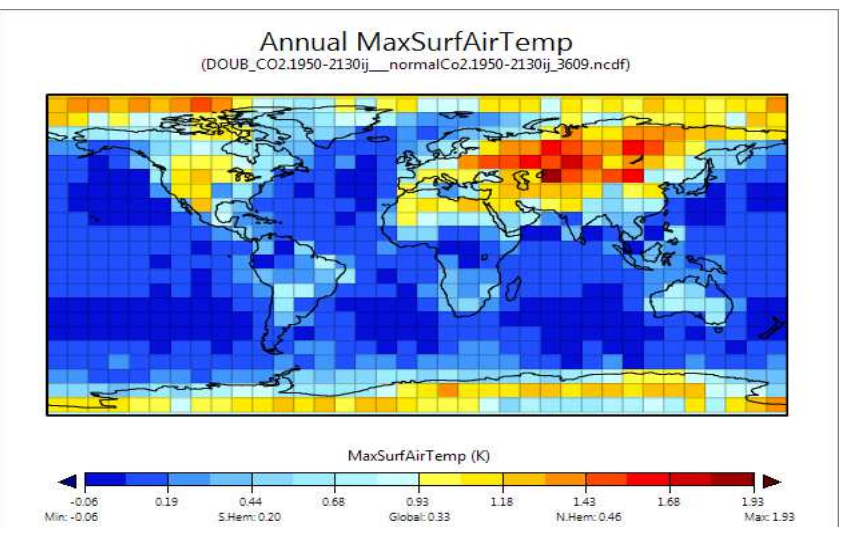

Fig. 3.7.2 Annual Minimum Surface Temperature

\subsubsection{Net Radiation at Planet}

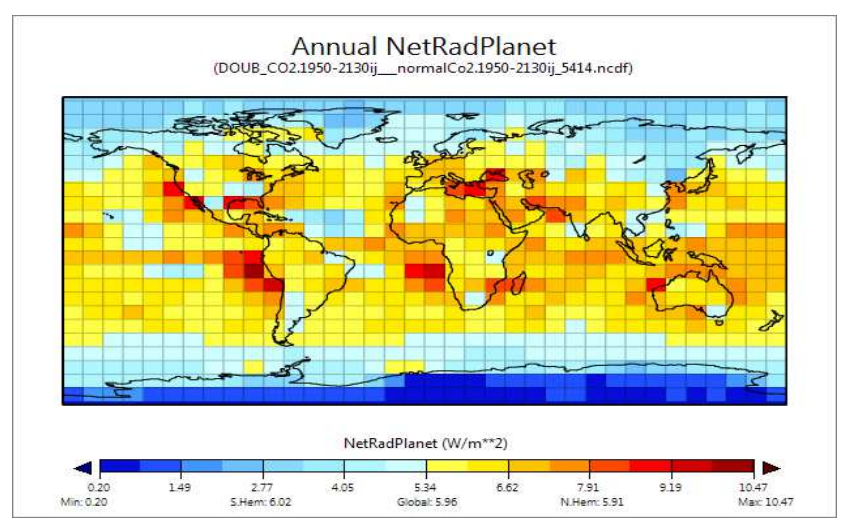

Fig. 3.7.3 Annual Net Radiation at Planet 


\section{CONCLUSIONS}

Rapid changes are occurring in the environment and which is having an adverse effect on the climatic condition due to large emission of greenhouse gases. As a consequence, monitoring and independent verification of reported anthropogenic emissions is becoming more and more important.

With the help of GCM model we are able to find the adverse effect of increase of $\mathrm{CO}_{2}$ on various important topics. It is clearly observable that the increase of $\mathrm{CO}_{2}$ is harming the environment rapidly. There are many other ill effects caused by increase of $\mathrm{CO}_{2}$, which are determined by the model but some of the main effects are focused in this report. Our earth will be in great trouble in future if proper steps to control the emissions are not implemented.

\section{REFERENCES}

[1]. Denman, K.L., G. Brasseur, A. Chidthaisong, P. Ciais, P.M. Cox, R.E. Dickinson, D. Hauglustaine, C. Heinze, E. Holland, D. Jacob, U. Lohmann, S Ramachandran, P.L. da Silva Dias, S.C. Wofsy and X. Zhang, 2007: Couplings Between Changes in the Climate System and Biogeochemistry. In: Climate Change 2007: The Physical Science Basis. Contribution of Working Group I to the Fourth Assessment Report of the Intergovernmental Panel on Climate Change [Solomon, S., D. Qin, M. Manning, Z. Chen, M. Marquis, K.B. Averyt, M.Tignor and H.L. Miller (eds.)]. Cambridge University Press, Cambridge, United Kingdom and New York, NY, USA.

[2]. Harvey, L.D.D., J. Gregory, M. Hoffert, A. Jain, M. Lal, R. Leemans, S.C.B. Raper, T.M.L. Wigley and J.R. de Wolde, 1997: An introduction to simple climate models used in the IPCC Second Assessment Report. IPCC Technical Paper 2, J.T. Houghton, L.G. Meira Filho, D.J. Griggs and K. Maskell (Eds.). IPCC, Geneva, Switzerland, 51 pp.

[3]. IPCC Special Report on Emissions Scenarios

[4]. IPCC Third Assessment Report - Climate Change 2001.

[5]. Oyama, M.D., and C.A. Nobre, 2004: Climatic consequences of a largescale desertification in northeast Brazil: a GCM simulation study. J. Clim., 17(16), 3203-3213.

[6]. Climate Models and Their Evaluation, David A. Randall (USA), Richard A. Wood (UK).

[7]. Anthony Lupo (USA) William Kininmonth (Australia) Contributing: J. Scott Armstrong (USA), Kesten Green (Australia), Global Climate Models and Their Limitations.

\section{BIOGRAPHIES}

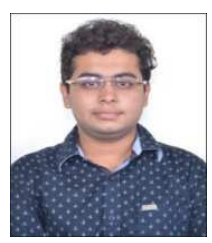

B.Tech $4^{\text {th }}$ year, Department of Civil Engineering, SRM University, Chennai, Tamil Nadu. Masters in Diploma in Building Design. Semester Abroad Program from MIT (Boston, USA).

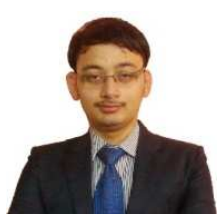

B.Tech $4^{\text {th }}$ year, Department of Civil Engineering, SRM University, Chennai, Tamil Nadu. Masters in Diploma in Building Design 